\title{
A Review of Power Distribution Test Feeders in the United States and the Need for Synthetic Representative Networks
}

\author{
Fernando E. Postigo Marcos ${ }^{1, *}$ (D), Carlos Mateo Domingo ${ }^{1}$, Tomás Gómez San Román ${ }^{1}$ (D), \\ Bryan Palmintier ${ }^{2}$, Bri-Mathias Hodge ${ }^{2}$, Venkat Krishnan ${ }^{2}$, Fernando de Cuadra García ${ }^{1}$ \\ and Barry Mather ${ }^{2}$ \\ 1 Institute for Research in Technology (IIT), Comillas Pontifical University, Madrid 28015, Spain; \\ carlos.mateo@comillas.edu (C.M.D.); tomas.gomez@comillas.edu (T.G.S.R.); \\ cuadra@icai.comillas.edu (F.d.C.G.) \\ 2 National Renewable Energy Laboratory (NREL), Golden, CO 80401, USA; bryan.palmintier@nrel.gov (B.P.); \\ Bri.Mathias.Hodge@nrel.gov (B.-M.H.); Venkat.Krishnan@nrel.gov (V.K.); Barry.Mather@nrel.gov (B.M.) \\ * Correspondence: fernando.postigo@comillas.edu; Tel.: +34-91-542-2800 (ext. 2729)
}

Received: 15 October 2017; Accepted: 14 November 2017; Published: 18 November 2017

\begin{abstract}
Under the increasing penetration of distributed energy resources and new smart network technologies, distribution utilities face new challenges and opportunities to ensure reliable operations, manage service quality, and reduce operational and investment costs. Simultaneously, the research community is developing algorithms for advanced controls and distribution automation that can help to address some of these challenges. However, there is a shortage of realistic test systems that are publically available for development, testing, and evaluation of such new algorithms. Concerns around revealing critical infrastructure details and customer privacy have severely limited the number of actual networks published and that are available for testing. In recent decades, several distribution test feeders and US-featured representative networks have been published, but the scale, complexity, and control data vary widely. This paper presents a first-of-a-kind structured literature review of published distribution test networks with a special emphasis on classifying their main characteristics and identifying the types of studies for which they have been used. This both aids researchers in choosing suitable test networks for their needs and highlights the opportunities and directions for further test system development. In particular, we highlight the need for building large-scale synthetic networks to overcome the identified drawbacks of current distribution test feeders.
\end{abstract}

Keywords: distribution networks; review; state of the art; test feeders; representative networks; distributed energy resources (DERs); synthetic distribution test feeders

\section{Introduction}

Current distribution networks are undergoing a transformation towards the smart grid paradigm, including rapid increases in the quantity of distributed energy resources (DERs). This has prompted considerable interest from the research and vendor communities to develop innovate tools and algorithms that are adapted to smart distribution networks that provide advanced controls and distribution automation. Tools like Optimal Power Flows (OPFs), Volt/Var optimization, or advanced feeder reconfiguration, enable evaluating specific operational and planning objectives, and thereby can help utilities to implement operational strategies. Some of the objectives commonly sought in these tools are the minimization of total system costs, the minimization of network losses, the maximization of security of supply or a mixture of all these objectives [1]. Moreover, countless studies have been conducted about the impact of DERs on distribution networks in recent years. For instance, 
under an active network management scheme, studies noted that DERs have the potential to reduce costs for consumers and utilities [2], highlighted the ability for coordinated controls to improve operations with high-penetration solar photovoltaic (PV) [3], explored the hosting capacity for DERs [4], and more.

However, the ability to test and analyze these trends and developments is limited by a scattered and somewhat incomplete set of public test systems. Distribution networks are sometimes considered as the critical infrastructure of a country, and detailed load/customer data prompts privacy concerns. As a result, only a very few actual networks are publically available for use as a test network. This has forced the research community to use only the available test feeders that are published in the literature so far, sometimes for purposes beyond the original intentions of the test feeder creators. For instance, in 1991, the Institute of Electrical and Electronics Engineers (IEEE) Power and Energy Society (PES) published four radial tests feeders providing references for the United States (US) distribution system for the first time. Now, 25 years after this first publication, the number of published US featured test feeders is still limited, despite significant dispersed efforts to add to the set of test feeders.

A test feeder is a distribution network model that is able to replicate the behavior of an actual distribution feeder [5]. In general, these test feeders aim to reproduce the characteristics of an actual network, including specific particularities within a specific region; this feature is called representativeness. In this case, we say that the test feeder is representative of a particular actual network located in a particular area or country. An important use of test feeders is benchmarking, allowing for researchers to evaluate the performance of their algorithms. For instance, in the OPF case, the computing time, the degree of optimality, or even a ratio between them can be used as a benchmark. With emerging widespread grid modernization efforts, testing the corresponding advanced optimization algorithms suggests a need for realistic large-scale distribution test networks. In addition to providing a valuable test platform, test networks are also essential to make consistent comparisons across different advanced algorithms.

This paper provides a comprehensive critical review of US-featured publically available test distribution networks-and their limitations-for use in evaluating and testing advanced OPF and related studies or analyzing DERs integration into smart distribution grids. This is intended to help researchers choose suitable test networks for their needs, while also highlighting opportunities and directions for further test system development. In addition, the paper includes new trends for, and emerging efforts in the creation of, large-scale synthetic distribution networks that could be provided as publically available test networks to the research community.

The paper is organized in the following manner. Section 2 develops a classification of published networks according to their origin, where each sub-section sheds light on different publicly available feeders, their summary features and intended uses. Section 2.1 analyzes the existing IEEE feeders. Section 2.2 studies the taxonomy feeders provided by the Pacific Northwest National Laboratory (PNNL). Section 2.3 examines the Electric Power Research Institute (EPRI) representative feeders. Section 2.4 inspects the prototypical feeders presented by the Pacific Gas and Electric Company (PG\&E). Section 2.5 reviews other the relevant test feeders that cannot be classified into the previous sections. Section 3 analyzes the limitations found in the currently available test feeders that were discussed in the previous sections, particularly from the perspective of developing advanced algorithms for advanced controls and distribution automation. Section 4 introduces the need for large-scale synthetic networks and for tools able to generate them. Finally, Section 5 presents the conclusions.

\section{Distribution Test Feeders}

A distribution network consists of power infrastructures that deliver electricity from the transmission/sub-transmission circuits to the final customers as shown in Figure 1. A wide variety of metrics could be defined to exhaustively characterize a distribution network. Nevertheless, there are some key descriptive components that can provide a simplified overview of it. In this review, we have 
described existing distribution test feeders using the metrics presented by respective authors or model creators in their publications, in order to be consistent with the original purposes for which these test feeders were created.

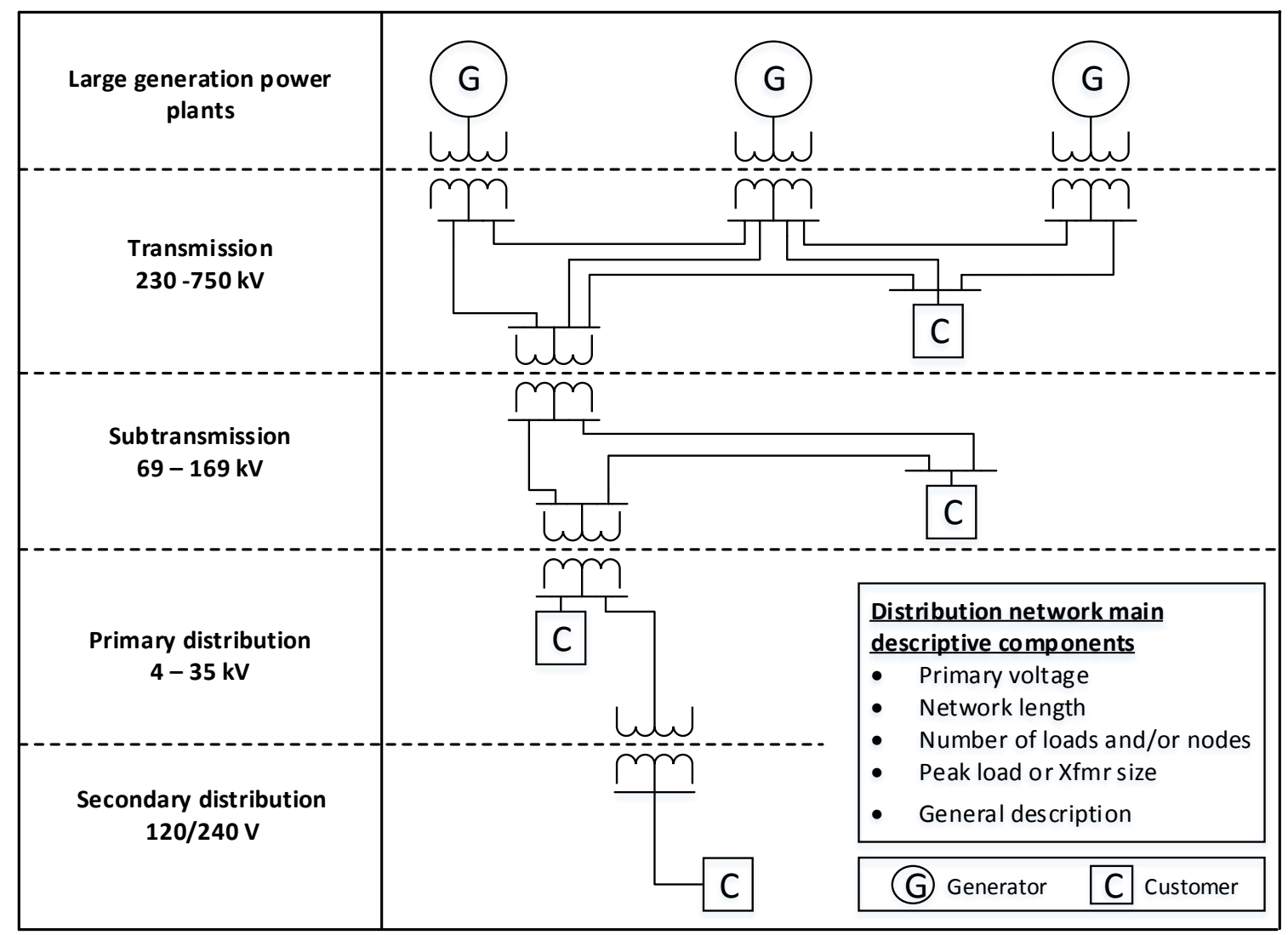

Figure 1. Power system infrastructure grouped by voltage levels.

Distribution test feeders can be built using different methods, as illustrated in Figure 2. The most straightforward one is the first method, which consists of selecting an actual feeder from a real distribution network, and anonymizing to remove private or sensitive data. The rest of the methods build synthetic networks, using real networks as the basis. The second method uses clustering techniques to group several actual networks and then stitches together pieces to build a synthetic representative test feeder for each group of actual networks. The third method builds a test feeder through manual design. This option allows for additional attention to be paid to specific network features but it is only possible with small-scale networks due to its complexity. Finally, the fourth method consists of building synthetic test networks through the use of planning tools that are designed to create realistic networks using the same technical and economic criteria that are used by distribution planners. This option allows for the design of new test networks from scratch with taylor made features. In general, the obtained test feeders should be representative of a set of real distribution networks with specific features. Representativeness is a validation criterion and therefore is not rigidly attached to any of the design methods, and it is possible to be obtained with any of the four described procedures.

In the next sections a bibliography review about the published test feeders is provided. Each section contains a brief description of the network and the most relevant publications where they are used. 


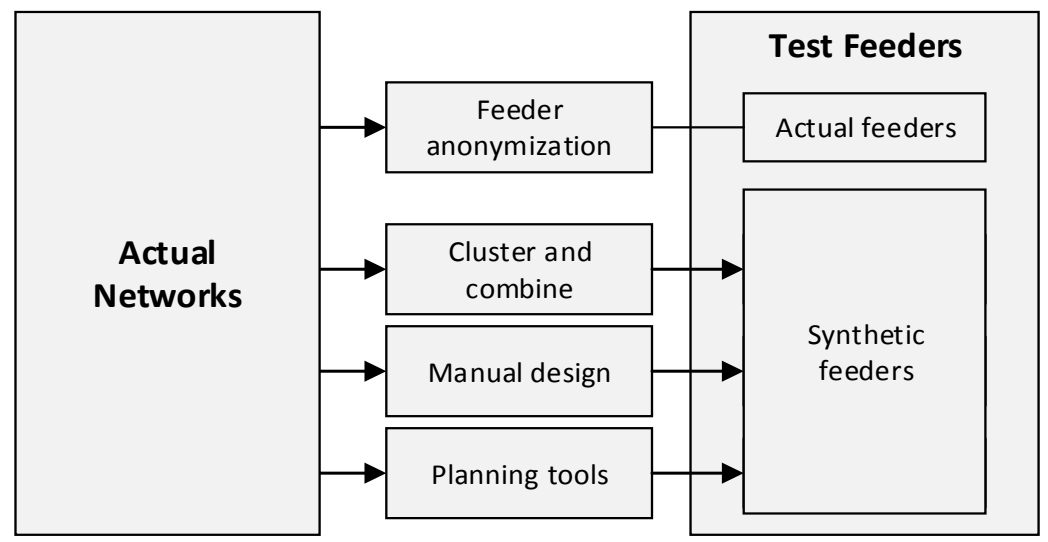

Figure 2. Test feeders building procedures.

\subsection{IEEE Feeders}

In 1991, the first set of four small test feeders was published [6] by the IEEE PES. Ten years later, a new test feeder was published [7] and was added to the previous set in order to provide a model of a three-phase transformer connection. In 2009, the Roadmap for the IEEE PES Test Feeder was published by the IEEE team [8]. In this paper, the direction and the requirements of the upcoming test feeders were presented, highlighting seven topics to take into account: neutral-to-earth voltage (NEV), short circuit benchmarks, distributed generation (DG) protections, large distribution system models, inverter-based DG models, comprehensive test feeders, and asymmetrical contingencies test feeders. Answering the previous needs, three new test feeders were published, a NEV test case [9], a medium-sized feeder to scale-up algorithms [10], and another with a wide variety of equipment [11]. In 2014, a new meshed low voltage test system was published [12]. The previous IEEE test feeders are presented chronologically. More information about these feeders is presented in Table 1. A recent publication [13], review the actual collection of test feeders and propose specific analytic challenges for future developments.

Table 1. Institute of Electrical and Electronics Engineers (IEEE) Test Feeders Features.

\begin{tabular}{cccccc}
\hline ID & Length (km) & Primary Voltage (kV) & $\begin{array}{c}\text { Number of } \\
\text { Customers/Loads }\end{array}$ & Peak load (MVA) & DG (MVA) \\
\hline 13 Node & 2.5 & 4.16 & 9 & 3.6 & 0 \\
123 Node & 12 & 4.16 & 114 & 3.8 & 0 \\
34 Node & 94 & 24.9 & 24 & 1.6 & 0 \\
37 Node & 5.5 & 4.8 & 25 & 2.73 & 0 \\
4 Node & 1.3 & 12.47 & 1 & 6.3 & 0 \\
NEV & 1.82 & 12.47 & 1 & 8.9 & 0 \\
8500 Node & 170 & 12.47 & 1177 & 11.1 & 0 \\
CTF & 81.7 & $12.47 / 24.9$ & 624 & 4.17 & 0.15 \\
342 Node & 15.2 & 13.2 & & 49.4 & 0 \\
\hline
\end{tabular}

\subsubsection{Node Test Feeder}

This small and highly loaded test feeder referred in [6] includes most of the common features that are used in actual networks like voltage regulators, shunt capacitor banks, overhead and underground lines, and unbalanced loads. This feeder provides a starting point to test power-flow convergence problems for a highly unbalanced system.

\subsubsection{Node Test Feeder}

This test feeder presented in [6] comprises of common characteristics that are installed in real networks. Several voltage drop problems are found in the feeder highlighting the necessity of voltage 
management with voltage regulators and shunt capacitor banks. It includes a number of switches to enable simple testing of intrafeeder reconfiguration strategies.

\subsubsection{Node Test Feeder}

This test feeder described in [6] is a part of a real distribution network located in Arizona. Due to the long length and the unbalanced nature of the feeder, power-flow convergence problems can be studied with this test feeder.

\subsubsection{Node Test Feeder}

Similar to the 34 Node Test Feeder, this feeder referred in [6] was obtained from an actual distribution network, in this case in California. The three-wire delta lines configuration is not common in US distribution networks; however, this model allows for testing algorithms in this less common environment.

\subsubsection{Node Test Feeder}

This test feeder presented in [7] was published ten years after the original IEEE test feeders. This test feeder offers a simple model for the analysis of all the available three-phase transformer connections as well as step-up and step-down operations under different scenarios of balanced and unbalanced loads.

Despite their small size, these test feeders are widely used in DERs studies [14-19] and power flow analysis $[20,21]$ among other types of studies.

\subsubsection{The Neutral-to-Earth Voltage Test Case and Distribution System Analysis}

The proliferation of harmonics that are generated by residential loads is producing an increase in the NEVs. Nowadays, modeling NEV is becoming an important issue, however, it requires more detailed test networks. This test case described in [9] provides a test feeder that explicitly includes pole ground resistances and aims to understand the impact on contact voltage levels and NEV under different parameters of neutral conductor section or ground resistance. This test case is mostly used in load modeling studies [22-24] and harmonics analysis [25].

\subsubsection{Node Test Feeder}

This test case referred in [10] was obtained from a real US distribution network with some light changes. The objective of this test feeder is to provide a large-scale reference network that allows for researchers to test algorithms on a more realistic and larger-scale system. Bus relative coordinates are included in the feeder data. It comprises several common North American features like a deep penetration of voltage regulators, per-phase capacitor banks, low-voltage secondaries, and centered-tapped transformers. It was published in two different versions, a balanced secondary-loading version, and a more realistic one with unbalanced secondaries. The primary voltage level is $12.47 \mathrm{kV}$ and the secondaries are split between $120-240 \mathrm{~V}$. This test feeder is widely used in smart grid and DER integration studies [26-28].

\subsubsection{Comprehensive Distribution Test Feeder (CTF)}

This test feeder presented in [11] aims to present a diverse and detailed network where most of the available configurations and equipment are included. The inclusion of switching devices allows for a range of network reconfiguration possibilities. This capability, combined with several different equipment types like overhead and underground lines, dissimilar transformers, step voltage regulators, induction machines, capacitor banks, and the mixture of distributed and spot unbalanced loads, results in a remarkably complete network where many possibilities can be tested. Despite being so complete, 
this test feeder has been designed for software testing issues, and outside of this application the results can be unrealistic. This test feeder is often used in smart grid analysis $[29,30]$.

\subsubsection{IEEE 342-Node Low Voltage Networked Test System (LVNTS)}

This test system described in [12] contains a set of eight $13.2 \mathrm{kV}$ primary feeders connected via delta/grounded-wye transformers to a low voltage meshed network in order to feed 50 MVA of unbalanced loads. The low voltage grid differentiates between the 120/208 V grid system (used in high-density areas) and the $277 / 480 \mathrm{~V}$ grid system (used in large load centers). The aim of this test system is to provide a reference for researchers whose objective is the evaluation of algorithms in non-radial distribution networks. This test system has been designed in order to deal with issues like heavily meshed systems with several parallel low voltage lines and transformers. This test feeder is mostly used in DERs studies [31], and communications planning analysis [32].

\subsection{PNNL Taxonomy Feeders}

The increasing penetration of smart grid technologies in the United States networks highlights the importance of the availability of test feeders that allow for studying the impact of their integration in a reliable way. Due to the large size of the country and the numerous different utilities, real networks present a wide range of differences in terms of topology and equipment used. For this reason, test feeders should reflect the differences due to parameters, such as climate region or voltage level.

In 2009, PNNL tried to answer this need with the publication of a set of 24 taxonomy radial distribution test feeders that are representative of the US continental area [33]. These synthetic distribution test feeders were developed through a clustering algorithm of 575 actual distribution feeders from 17 different utilities. To carry out this classification, the US was divided into five climate regions, where 35 relevant statistical and electrical properties were studied. A full description about the nature of each feeder is provided in the report [34], and are succinctly summarized in Table 2. This set of feeders is mostly used in DERs studies [35,36], and reliability analysis [36,37].

Table 2. Pacific Northwest National Laboratory (PNNL) Taxonomy Feeders.

\begin{tabular}{|c|c|c|c|c|}
\hline ID & $\begin{array}{c}\text { Primary } \\
\text { Voltage (kV) }\end{array}$ & $\begin{array}{l}\text { Peak Load } \\
\text { (MVA) }\end{array}$ & Nodes & Description \\
\hline R1-12.47-1 & 12.5 & 7152 & 613 & Moderate suburban and rural \\
\hline R1-12.47-2 & 12.47 & 2836 & 337 & Moderate suburban and light rural \\
\hline R1-12.47-3 & 12.47 & 1362 & 52 & Small urban center \\
\hline $\mathrm{R} 1-12.47-4$ & 12.47 & 5334 & 302 & Heavy suburban \\
\hline R1-25.00-1 & 24.9 & 2105 & 323 & Light rural \\
\hline R2-12.47-1 & 12.47 & 6046 & 482 & Light urban \\
\hline $\mathrm{R} 2-12.47-2$ & 12.47 & 6098 & 250 & Moderate suburban \\
\hline R2-12.47-3 & 12.47 & 1411 & 768 & Light suburban \\
\hline $\mathrm{R} 2-25.00-1$ & 24.9 & 17,021 & 317 & Moderate urban \\
\hline R2-35.00-1 & 34.5 & 8893 & 1031 & Light rural \\
\hline R3-12.47-1 & 12.47 & 8417 & 633 & Heavy urban \\
\hline R3-12.47-2 & 12.47 & 4322 & 263 & Moderate urban \\
\hline R3-12.47-3 & 12.47 & 7880 & 2000 & Heavy suburban \\
\hline R4-12.47-1 & 13.8 & 5530 & 571 & Heavy urban with rural spur \\
\hline R4-12.47-2 & 12.5 & 2218 & 263 & Light suburban and moderate urban \\
\hline R4-25.00-1 & 24.9 & 948 & 230 & Light rural \\
\hline R5-12.47-1 & 13.8 & 9430 & 265 & Heavy suburban and moderate urban \\
\hline R5-12.47-2 & 12.47 & 4500 & 311 & Moderate suburban and heavy urban \\
\hline R5-12.47-3 & 13.8 & 9200 & 1468 & Moderate rural \\
\hline R5-12.47-4 & 12.47 & 7700 & 643 & Moderate suburban and urban \\
\hline R5-12.47-5 & 12.47 & 8700 & 1075 & Moderate suburban and light urban \\
\hline R5-25.00-1 & 22.9 & 12,050 & 946 & Heavy suburban and moderate urban \\
\hline R5-35.00-1 & 34.5 & 11,800 & 338 & Moderate suburban and light urban \\
\hline GC-12.47-1 & 12.47 & 5200 & 27 & Single large commercial or industrial \\
\hline
\end{tabular}




\subsection{EPRI Representative Feeders}

EPRI provides a set of six large representative feeders (J1, K1, M1, Ckt5, Ckt7, and Ckt24) obtained from real networks. Bus relative coordinates and time series data are included in all feeder's data in order to provide more realistic cases.

Three of the feeders (J1, K1, and M1) are deeply focused on assessing the impact of different levels of distributed photovoltaic (PV) penetration. Table 3 summarizes the main parameters of these test feeders.

Table 3. The Electric Power Research Institute (EPRI) Test Feeders 1.

\begin{tabular}{cccccc}
\hline ID & $\begin{array}{c}\text { Primary } \\
\text { Length } \mathbf{( k m )}\end{array}$ & $\begin{array}{c}\text { Primary } \\
\text { Voltage } \mathbf{( k V )}\end{array}$ & $\begin{array}{c}\text { Number of } \\
\text { Customers/Loads }\end{array}$ & Peak Load (MW) & DG (MW) \\
\hline Feeder J1 & 93.3 & 12.47 & 1384 & 6 & 1.7 \\
Feeder K1 & 45.1 & 13.2 & 321 & 6 & 1 \\
Feeder M1 & 20.9 & 12.47 & 1470 & 5.5 & - \\
\hline
\end{tabular}

\subsubsection{Feeder J1}

This is a real feeder located in the Northeastern United States and is referred in [38]. It is composed of residential, commercial, and light industrial customers. This feeder models 1.7 MW of customer-owned PV systems, along with voltage regulators and capacitor banks. Customers have noted overvoltage problems that are assumed to be caused by PV and a slow load tap changer (LTC). This test feeder's goal is to find solutions in areas with overvoltage.

\subsubsection{Feeder K1}

This is a real feeder that is located in the Southeastern United States and is presented in [39]. It is composed of commercial and residential customers. This feeder models $1 \mathrm{MW}$ of customer-owned PV systems. A substation LTC provides the voltage regulation as well as a capacitor bank that is placed mid-feeder. No voltage regulators are included. The objective of this test feeder is to test power flow solutions in environments with high penetrations of customer-owned PV without voltage regulators.

\subsubsection{Feeder M1}

This feeder described in [40] provides a detailed model of secondary feeders. It models reactive compensation that is offered by three-phase radio-controlled capacitor banks. The aim of this test feeder is to test capacitor bank management strategies in order to set a proper power factor.

\subsubsection{Ckt 5, Ckt 7 and Ckt 24}

These large-scale test networks referred in [41] allow testing power flows in smart grid environments. Table 4 summarizes the main parameters of these test feeders.

Table 4. EPRI Test Feeders 2.

\begin{tabular}{cccccc}
\hline ID & $\begin{array}{c}\text { Primary } \\
\text { Length }(\mathbf{k m})\end{array}$ & $\begin{array}{c}\text { Primary } \\
\text { Voltage } \mathbf{( k V )}\end{array}$ & $\begin{array}{c}\text { Number of } \\
\text { Customers/Loads }\end{array}$ & $\begin{array}{c}\text { Xfmr Size } \\
\mathbf{( M V A )}\end{array}$ & $\begin{array}{c}\text { Number of } \\
\text { Feeders }\end{array}$ \\
\hline Ckt 5 & 77.2 & 12.47 & 1379 & 16.31 & 1 \\
Ckt 7 & 12.9 & 12.5 & 5694 & 19.32 & 14 \\
Ckt 24 & 119.1 & 34.5 & 3885 & 69.37 & 2 \\
\hline
\end{tabular}

These networks are mainly used in studies about high-penetration PV environments, where Volt/Var control strategies are needed to overcome overvoltage problems [42-44]. 


\subsection{PGEE Prototypical Feeders}

This set of 12 test feeders presented in [45] offers a taxonomy of the major type of networks that are observed in PG\&E's system. They are obtained through a clustering process of 2700 primary distribution feeders. Different kinds of networks, with a wide variety of sizes (from approximately 100 nodes to 2000 nodes) and customers mixes are represented in this compilation. The aim of these test feeders is to test the impact of DERs under different scenarios.

\subsection{Other Test Feeders}

Many other test feeders have been used in papers to study different issues, however, only a few of them are publically available for the research community. In what follows, several test feeders that have been published and cannot be classified in the previous groups are presented. Some of these feeders were intended to address the request presented in [8].

\subsubsection{Benchmark Models for Low-Voltage Distribution Feeders}

This test feeder described in [46] aims to reproduce the characteristics of a real and standard low voltage network. During the design process, a differentiation between residential, industrial, and commercial subnetworks has been made, adjusting equipment and features to the nature of the customer. A deep dive into the layout and geometry of the typical overhead and underground lines is also performed. This test feeder is used in network management analysis [47-49].

\subsubsection{Agent-Based Distribution Test Feeder with Smart-Grid Functionality}

This $13.2 \mathrm{kV}$ test feeder referred in [50] is obtained from a real distribution network in Iowa where the peak power is close to 14 MVA. Customers are equipped with several smart-grid features, like rooftop PV panels, and price-responsive loads with time series data (e.g., smart air-conditioning devices and electric vehicles). The objective of this test feeder is to provide a tool that enables the analysis of wholesale electric power markets joined with the features of an actual feeder with smart-grid technologies. This test feeder is used in smart-grid studies [51] and planning process analysis [52,53].

\subsubsection{Test Feeder for DG Protection Analysis}

This $12.47 \mathrm{kV}$ test feeder presented in [54] is extracted from an actual network with weak sub-transmission source impedance connected to a $1.65 \mathrm{MW}$ wind turbine. The aim of this test feeder is to provide a benchmark that allows for testing distributed generation protection elements under four different fault scenarios. This test feeder has been used in power flow analysis [55].

\section{Limitations of Previous Test Feeders}

Distribution test networks, representing large regions and matching realistic utility features, become necessary for the development of advanced distribution tools, like OPFs, Volt/Var optimization, or network reconfiguration algorithms. The previously described set of test feeders presents a number of limitations that make their use for advanced distribution system applications difficult. Among these limitations we have found some common ones, such as: their small size, the lack of time series data representing demand and generation variability, the absence of representativeness, the lack of geographical coordinates for the physical layout of the network, test feeders that were created for dealing with a single technical or economic issue and do not have sufficient information necessary for other applications, or isolated feeders. In what follows, these limitations are analyzed in more detail. It is important to note that each of these features are present individually in a number of the available test feeders, however, the majority of the available test feeders only contain a small sub-set of the desired characteristics. Common limitations include:

- Smaller sizes: The size of the network is an important issue that should be considered in order to extract reliable conclusions from the studies. This paper proposes the use of the term "large-scale" 
only when multiple feeders that are connected to a substation are taken into account. In most of the cases, large-scale networks capture more heterogeneity in some factors like voltage levels, equipment variety, or network configurations. This leads to more scalable and robust results and conclusions. Nevertheless, the computational time increases dramatically when the size of the problem increases. The size of the existing test feeders is generally small, the largest ones being the 8500 node test feeder and the EPRI feeders. However, these medium-size test systems are not enough to verify the performance of large-scale solutions that are provided by new algorithms.

- Lack of time series data: Time series data for demands and DERs allow for a more comprehensive analysis of network operations. For example, the integration of DERs, such as battery storage devices with time constraints for their optimal management (due to their storage capacity), makes necessary the use of time series data during the study period of interest. In these cases, the standard single-period OPF should be transformed to a multi-period optimization. Multi-period OPFs allow for solutions that consider temporal constraints from DERs, such as energy storage, electric vehicles, or demand response. For instance, the presented EPRI test feeders (Section 2.3) include time series data with different profiles for the loads.

- Lack of representativeness: The representativeness of a distribution test network is related to the specific zonal characteristics of actual networks. For instance, unlike in Europe, US primary feeders consist of three-phase and single-phase feeder sections that supply electricity in the particular coverage zones. In addition, the number of customers powered by a single medium-voltage/low-voltage distribution transformer in the United States is much smaller than in Europe, as well as the size of the transformer itself. As a consequence, in the United States, the length of low voltage networks is also shorter than in Europe. Another notable difference is the layout of the feeders. In Europe, the vast majority of feeders within urban areas are underground. However, in the United States, underground feeders are limited to some specific residential and commercial areas. In general, urban networks have higher load density than rural networks. The type of network topologies and the type of network equipment can change depending on that the geographic and development considerations of a particular region. For instance, rural networks are topologically much more radial, and the existence of loops connecting different feeders is much less frequent than in urban networks. Finally, the type of equipment that is used by utilities changes from country to country or from region to region. For instance, the presented IEEE 8500 node test feeder includes the detailed characteristics of center-tapped MV/LV distribution transformers used in the United States.

- Missing geographical coordinates: Customer coordinates are not relevant for electrical calculations; however, they give a useful topological image of the network layout. These topological issues play an important role in expansion planning and potential reconfiguration strategies in case of network failures. For instance, the IEEE 8500 node test feeder, as well as the EPRI test feeders, include the geographical coordinates of the different network nodes.

- Design and data available for only a single issue: Some of the described test feeders were designed with the objective of modeling and solving a specific technical or economic operational problem, and in general, they become unsuitable to be used in other types of problems or applications due to the lack of relevant information. One example of this case is the presented Test Feeder for DG Protection Analysis.

- Isolated feeders: Nearly all the existing distribution test systems contain only a single, isolated feeder. This effectively ignores capture voltage and other interactions between feeders that share a substation transformer and complicates testing reconfiguration using feeder-to-feeder switching commonly used for maintenance and fault recovery. 


\section{Need for Large-Scale Test Networks}

As described above, the vast majority of the described test feeders have a variety of limitations. In particular, the research community lacks large-scale and representative test networks making it difficult to check the validity of developed algorithms and to perform reliable and scalable operational and planning studies. This is one of the reasons why public institutions are funding projects that aim to obtain a new generation of test feeders that remove current limitations while keeping the technical rigor present in some of the current test feeders is discussed in Section 2 [56].

Several planning tools that are capable of creating synthetic networks have been developed and reported in the technical literature during the last decade. These planning models are able to locate and size primary and secondary circuits, as well as distribution transformers, through mathematical programming or heuristic algorithms. Earlier efforts with mathematical programming methods like mixed integer linear programming [57] or nonlinear programming [58], are being replaced by heuristic methods like genetic algorithms [59], practical heuristic algorithms [60], or particle swarm optimization [61]. The increasing use of heuristic methods over numerical ones is driven by the computational complexity of planning entire distribution systems. The use of heuristics is particularly relevant for distribution planning because of the much larger node count when compared to transmission network planning. These past efforts have shown that heuristic methods can be dramatically faster and more robust, which becomes especially important when planning large-scale networks.

In Europe, there have been some past efforts to build "reference network models" that can automate the design and layout large-scale distribution networks [60]. Reference network models use heuristics to generate synthetic representative networks from scratch and were originally developed to overcome the information gap that was faced by regulators in assessing appropriate utility costs. Their rich modeling framework make them capable of fulfilling the criteria described in the previous sections. An overview of the main components of such a reference network model is shown in Figure 3, which highlights the various inputs and outputs that a reference network model could use for creating advanced synthetic test feeders for future use cases. However, there are major design differences between the US and Europe, making these past tools unsuitable for use in building US-style networks. Among many other differences, the US use of extensive single-phase segments considerably increases the complexity of developing a reference network model for the US.

INPUTS

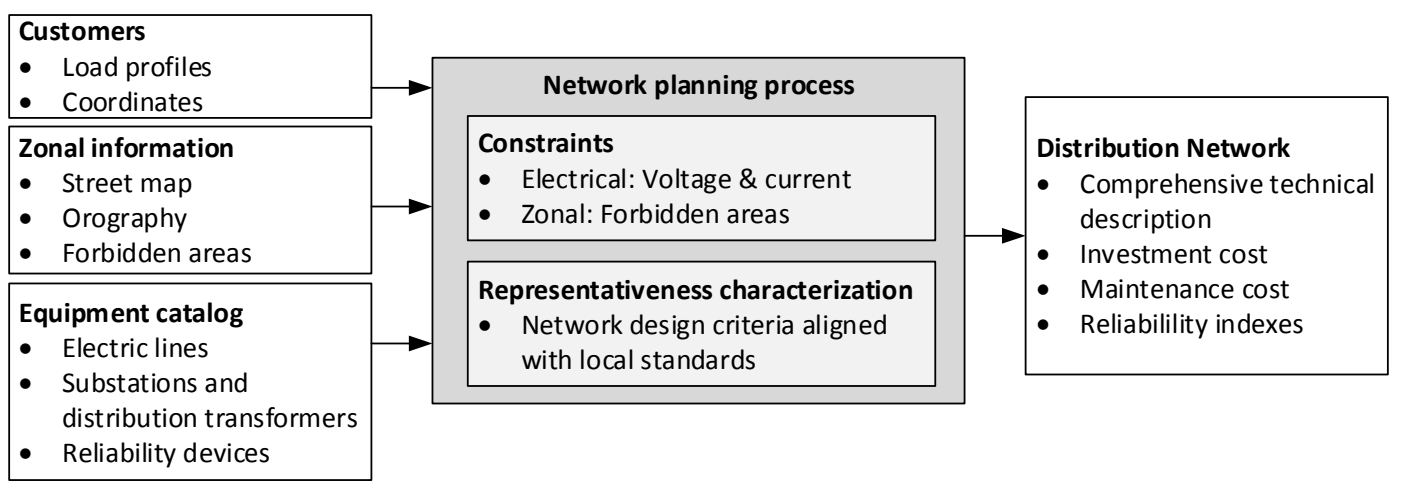

Figure 3. Components of a reference network model proposed for developing advanced, large-scale test systems.

\section{Conclusions}

Based on the needs of utilities and the scientific community under the new paradigm of smart distribution grids and DER integration, this paper has presented a comprehensive review of the US 
distribution test feeders published over the last three decades. The paper presented a succinct analysis of all the feeders, classified them based on their origin and intended uses or applications, systematically delineated all of the limitations, and identified future research needs in this field related to test feeder generation. The first set of test feeders includes small, purely radial, and non-representative distribution networks that were effective at the time and for specific intent, but have been overused in unintended ways. However, the observed trend in the test feeders published in the last years is to build large-scale representative networks with reconfiguration capabilities and are able to model several technical and economic operational and planning issues; for instance, the ones that are associated with the integration of DERs under different future scenarios. Planning tools based on numerical and heuristic methods, such as reference network models, are opening new research areas in order to design these required large-scale realistic networks and make them suitable for validating and comparing advanced distribution system algorithms.

Acknowledgments: This work was supported by the U.S. Department of Energy under Contract No. DE-AC36-08GO28308 with Alliance for Sustainable Energy, LLC, the Manager and Operator of the National Renewable Energy Laboratory. Funding for this work was provided by Advanced Research Projects Agency-Energy (ARPA-E). The U.S. Government retains and the publisher, by accepting the article for publication, acknowledges that the U.S. Government retains a nonexclusive, paid-up, irrevocable, worldwide license to publish or reproduce the published form of this work, or allow others to do so, for U.S. Government purposes.

Author Contributions: F.E.P.M. carried out the state of the art review during his Ph.D. research. C.M.D. and T.G.S.R. supervised this work. F.E.P.M., C.M.D., T.G.S.R., B.P., B.-M.H., V.K., F.d.C.G. and B.M. contributed to the preparation of the manuscript.

Conflicts of Interest: The authors declare no conflict of interest.

\section{References}

1. Bacher, R. Power System Models, Objectives and Constraints in Optimal Power Flow Calculations. In Optimization in Planning and Operation of Electric Power Systems; Physica: Heidelberg, Germany, 1993; pp. 217-263.

2. Pérez-Arriaga, J.I.; Batlle, C.; Gómez, T.; Chaves, J.P.; Rodilla, P.; Herrero, I.; Dueñas, P.; Ramírez, C.R.V.; Bharatkumar, A.; Burger, S.; et al. Utility of the Future: An MIT Energy Initiative Response to an Industry in Transition; Massachusetts Institute of Technology: Cambridge, MA, USA, 2016.

3. Palmintier, B.; Giraldez, J.; Gruchalla, K.; Gotseff, P.; Nagarajan, A.; Harris, T.; Bugbee, B.; Baggu, M.; Gantz, J.; Boardman, E. Feeder Voltage Regulation with High Penetration PV Using Advanced Inverters and a Distribution Management System: A Duke Energy Case Study; NREL Technical Report NREL/TP-5D00-65551; National Renewable Energy Laboratory: Golden, CO, USA, 2016.

4. Hoke, A.; Butler, R.; Hambrick, J.; Kroposki, B. Steady-State Analysis of Maximum Photovoltaic Penetration Levels on Typical Distribution Feeders. IEEE Trans. Sustain. Energy 2013, 4, 350-357. [CrossRef]

5. Rodriguez-Calvo, A. Scalability and Replicability of the Impact of Smart Grid Solutions on Distribution Networks. Ph.D. Thesis, Universidad Pontificia Comillas, Madrid, Spain, 2017.

6. Kersting, W.H. Radial distribution test feeders. IEEE Trans. Power Syst. 1991, 6, 975-985. [CrossRef]

7. Kersting, W.H. Radial distribution test feeders. In Proceedings of the 2001 IEEE Power Engineering Society Winter Meeting (Cat. No.01CH37194), Columbus, OH, USA, 28 January-1 February 2001; Volume 2, pp. 908-912.

8. Dugan, R.C.; Kersting, W.H.; Carneiro, S.; Arritt, R.F.; McDermott, T.E. Roadmap for the IEEE PES test feeders. In Proceedings of the 2009 IEEE/PES Power Systems Conference and Exposition, Seattle, WA, USA, 15-18 March 2009; pp. 1-4.

9. Sunderman, W.G.; Dugan, R.C.; Dorr, D.S. The neutral-to-earth voltage (NEV) test case and distribution system analysis. In Proceedings of the 2008 IEEE Power and Energy Society General Meeting-Conversion and Delivery of Electrical Energy in the 21st Century, Pittsburgh, PA, USA, 20-24 July 2008; pp. 1-6.

10. Arritt, R.F.; Dugan, R.C. The IEEE 8500-node test feeder. In Proceedings of the 2010 IEEE PES Transmission and Distribution Conference and Exposition, New Orleans, LA, USA, 19-22 April 2010; pp. 1-6.

11. Kersting, W.H. A comprehensive distribution test feeder. In Proceedings of the 2010 IEEE PES Transmission and Distribution Conference and Exposition, New Orleans, LA, USA, 19-22 April 2010; pp. 1-4. 
12. Schneider, K.; Phanivong, P.; Lacroix, J.S. IEEE 342-node low voltage networked test system. In Proceedings of the 2014 IEEE PES General Meeting I Conference Exposition, National Harbor, MD, USA, 27-31 July 2014; pp. 1-5.

13. Schneider, K.P.; Schnider, K.; Mather, B.A.; Pal, B.C.; Ten, C.-W.; Shirek, G.; Zhu, H.; Fuller, J.; Pereira, J.L.R.; Ochoa, L.; et al. Analytic Considerations and Design Basis for the IEEE Distribution Test Feeders. IEEE Trans. Power Syst. 2017, PP, 1. [CrossRef]

14. Jang, S.-I.; Kim, K.-H. An islanding detection method for distributed generations using voltage unbalance and total harmonic distortion of current. IEEE Trans. Power Deliv. 2004, 19, 745-752. [CrossRef]

15. Quezada, V.H.M.; Abbad, J.R.; Roman, T.G.S. Assessment of energy distribution losses for increasing penetration of distributed generation. IEEE Trans. Power Syst. 2006, 21, 533-540.

16. Ochoa, L.F.; Padilha-Feltrin, A.; Harrison, G.P. Evaluating distributed generation impacts with a multiobjective index. IEEE Trans. Power Deliv. 2006, 21, 1452-1458. [CrossRef]

17. Timbus, A.; Larsson, M.; Yuen, C. Active Management of Distributed Energy Resources Using Standardized Communications and Modern Information Technologies. IEEE Trans. Ind. Electron. 2009, 56, 4029-4037. [CrossRef]

18. Clement-Nyns, K.; Haesen, E.; Driesen, J. The Impact of Charging Plug-in Hybrid Electric Vehicles on a Residential Distribution Grid. IEEE Trans. Power Syst. 2010, 25, 371-380. [CrossRef]

19. Clement-Nyns, K.; Haesen, E.; Driesen, J. The impact of vehicle-to-grid on the distribution grid. Electr. Power Syst. Res. 2011, 81, 185-192. [CrossRef]

20. Khushalani, S.; Solanki, J.M.; Schulz, N.N. Development of Three-Phase Unbalanced Power Flow Using PV and PQ Models for Distributed Generation and Study of the Impact of DG Models. IEEE Trans. Power Syst. 2007, 22, 1019-1025. [CrossRef]

21. Dall'Anese, E.; Zhu, H.; Giannakis, G.B. Distributed optimal power flow for smart microgrids. IEEE Trans. Smart Grid 2013, 4, 1464-1475. [CrossRef]

22. Schneider, K.P.; Fuller, J.C. Detailed end use load modeling for distribution system analysis. In Proceedings of the IEEE Power and Energy Society General Meeting, Providence, RI, USA, 25-29 July 2010; pp. 1-7.

23. Schneider, K.P.; Fuller, J.C.; Chassin, D.P. Multi-State Load Models for Distribution System Analysis. IEEE Trans. Power Syst. 2011, 26, 2425-2433. [CrossRef]

24. Horton, R.; Sunderman, W.G.; Arritt, R.F.; Dugan, R.C. Effect of line modeling methods on neutral-to-earth voltage analysis of multi-grounded distribution feeders. In Proceedings of the 2011 IEEE/PES Power Systems Conference and Exposition, Phoenix, AZ, USA, 20-23 March 2011; pp. 1-6.

25. Variz, A.M.; Pereira, J.L.R.; Carneiro, J.; Barbosa, P.G. Harmonic analysis of the power distribution Neutral-to-Earth Voltage (NEV) test case using four-wire three-phase harmonic current injection method. In Proceedings of the 2009 IEEE Power and Energy Society General Meeting, Calgary, AB, Canada, 26-30 July 2009.

26. Arritt, R.F.; Dugan, R.C. Distribution system analysis and the future smart grid. IEEE Trans. Ind. Appl. 2011, 47, 2343-2350. [CrossRef]

27. Dugan, R.C.; McDermott, T.E. An open source platform for collaborating on smart grid research. In Proceedings of the IEEE Power and Energy Society General Meeting, Detroit, MI, USA, 24-29 July 2011.

28. Venkatesan, N.; Solanki, J.; Solanki, S.K. Residential Demand Response model and impact on voltage profile and losses of an electric distribution network. Appl. Energy 2012, 96, 84-91. [CrossRef]

29. Rui, H.; Arnold, M.; Wellssow, W.H. Synthetic medium voltage grids for the assessment of Smart Grid techniques. In Proceedings of the IEEE PES Innovative Smart Grid Technologies Conference Europe, Berlin, Germany, 14-17 October 2012.

30. Hooshyar, H.; Mahmood, F.; Vanfretti, L.; Baudette, M. Specification, implementation, and hardware-in-the-loop real-time simulation of an active distribution grid. Sustain. Energy Grids Netw. 2015, 3, 36-51. [CrossRef]

31. Yuan, Z.; Hesamzadeh, M.R. Hierarchical coordination of TSO-DSO economic dispatch considering large-scale integration of distributed energy resources. Appl. Energy 2017, 195, 600-615. [CrossRef]

32. Yang, T.; Huang, Z.; Pen, H.; Zhang, Y. Optimal Planning of Communication System of CPS for Distribution Network. J. Sens. 2017, 2017, 9303989. [CrossRef]

33. Schneider, K.P.; Chen, Y.; Engle, D.; Chassin, D. A Taxonomy of North American radial distribution feeders. In Proceedings of the 2009 IEEE Power Energy Society General Meeting, Calgary, AB, Canada, 26-30 July 2009; pp. 1-6. 
34. Schneider, K.P.; Chen, Y.; Chassin, D.P.; Pratt, R.; Enge, D.; Thompson, S. Modern Grid Initiative Distribution Taxonomy Final Report; Pacific Northwest National Laboratory (PNNL): Richland, WA, USA, 2008.

35. Wu, D.; Cai, C.; Aliprantis, D.C. Potential impacts of aggregator-controlled plug-in electric vehicles on distribution systems. In Proceedings of the 2011 4th IEEE International Workshop on Computational Advances in Multi-Sensor Adaptive Processing (CAMSAP 2011), San Juan, Puerto Rico, 13-16 December 2011; pp. 105-108.

36. Jahangiri, P.; Aliprantis, D.C. Distributed Volt/VAr control by PV inverters. IEEE Trans. Power Syst. 2013, 28, 3429-3439. [CrossRef]

37. Xu, Y.; Liu, C.-C.; Gao, H. Reliability analysis of distribution systems considering service restoration. In Proceedings of the 2015 IEEE Power and Energy Society Innovative Smart Grid Technologies Conference, Washington, DC, USA, 18-20 February 2015.

38. Electric Power Research Institute (EPRI). EPRI Feeder J1. Available online: http:/ /dpv.epri.com/feeder_j. html (accessed on 30 March 2017).

39. Electric Power Research Institute (EPRI). EPRI Feeder K1. Available online: http://dpv.epri.com/feeder_k. html (accessed on 30 March 2017).

40. Electric Power Research Institute (EPRI). EPRI Feeder M1. Available online: http://dpv.epri.com/feeder_m. html (accessed on 30 March 2017).

41. Electric Power Research Institute (EPRI). EPRI Test Circuits. Available online: https:/ / sourceforge.net/p/ electricdss/code/HEAD/tree/trunk/Distrib/EPRITestCircuits/Readme.pdf (accessed on 28 April 2017).

42. Kim, I.; Harley, R.G.; Regassa, R.; Valle, Y.D. The effect of the volt/var control of photovoltaic systems on the time-series steady-state analysis of a distribution network. In Proceedings of the 2015 Clemson University Power Systems Conference (PSC), Clemson, SC, USA, 10-13 March 2015; pp. 1-6.

43. Kim, I.; Harley, R.G. A study on the effect of the high-penetration photovoltaic system on an increase in overvoltage of distribution feeders. In Proceedings of the 2015 North American Power Symposium (NAPS), Charlotte, NC, USA, 4-6 October 2015; pp. 1-4.

44. Reno, M.J.; Coogan, K.; Grijalva, S.; Broderick, R.J.; Quiroz, J.E. PV interconnection risk analysis through distribution system impact signatures and feeder zones. In Proceedings of the 2014 IEEE PES General Meeting I Conference Exposition, National Harbor, MD, USA, 27-31 July 2014; pp. 1-5.

45. Pacific Gas and Electric Prototypical Feeder Models. Available online: http://gridlab-d.shoutwiki.com/ wiki/PGE_Prototypical_Models (accessed on 15 October 2017).

46. Strunz, K.; Fletcher, R.H.; Campbell, R.; Gao, F. Developing benchmark models for low-voltage distribution feeders. In Proceedings of the 2009 IEEE Power Energy Society General Meeting, Calgary, AB, Canada, 26-30 July 2009; pp. 1-3.

47. Li, Y.; Li, Y.W. Virtual frequency-voltage frame control of inverter based low voltage microgrid. In Proceedings of the 2009 IEEE Electrical Power and Energy Conference (EPEC), Montreal, QC, Canada, 22-23 October 2009.

48. Li, Y.; Li, Y.W. Power management of inverter interfaced autonomous microgrid based on virtual frequency-voltage frame. IEEE Trans. Smart Grid 2011, 2, 18-28. [CrossRef]

49. Zamani, M.A.; Sidhu, T.S.; Yazdani, A. A protection strategy and microprocessor-based relay for low-voltage microgrids. IEEE Trans. Power Deliv. 2011, 26, 1873-1883. [CrossRef]

50. Jahangiri, P.; Wu, D.; Li, W.; Aliprantis, D.C.; Tesfatsion, L. Development of an agent-based distribution test feeder with smart-grid functionality. In Proceedings of the 2012 IEEE Power and Energy Society General Meeting, San Diego, CA, USA, 22-26 July 2012; pp. 1-7.

51. Vrba, P.; Mařík, V.; Siano, P.; Leitão, P.; Zhabelova, G.; Vyatkin, V.; Strasser, T. A review of agent and service-oriented concepts applied to intelligent energy systems. IEEE Trans. Ind. Inform. 2014, 10, 1890-1903. [CrossRef]

52. Kays, J.; Seack, A.; Häger, U. Consideration of innovative distribution grid operation concepts in the planning process. In Proceedings of the IEEE PES Innovative Smart Grid Technologies Conference Europe, Ljubljana, Slovenia, 9-12 October 2017.

53. Kays, J.; Rehtanz, C. Planning process for distribution grids based on flexibly generated time series considering RES, DSM and storages. IET Gener. Transm. Distrib. 2016, 10, 3405-3412. [CrossRef]

54. McDermott, T.E. A test feeder for DG protection analysis. In Proceedings of the 2011 IEEE/PES Power Systems Conference and Exposition, Phoenix, AZ, USA, 20-23 March 2011; pp. 1-7. 
55. Wieserman, L.; McDermott, T.E. Fault current and overvoltage calculations for inverter-based generation using symmetrical components. In Proceedings of the 2014 IEEE Energy Conversion Congress and Exposition, Pittsburgh, PA, USA, 14-18 September 2014; pp. 2619-2624.

56. National Renewable Energy Laboratory (NREL). SMARtDaTa: Standardized multi-scale Models of Anonymized Realistic Distribution and Transmission Data. Available online: https: / arpa-e.energy.gov / ?q=slick-sheet-project/smartdata-grid-models (accessed on 15 October 2017).

57. Paiva, P.C.; Khodr, H.M.; Dominguez-Navarro, J.A.; Yusta, J.M.; Urdaneta, A.J. Integral planning of primary-secondary distribution systems using mixed integer linear programming. IEEE Trans. Power Syst. 2005, 20, 1134-1143. [CrossRef]

58. Fletcher, R.H.; Strunz, K. Optimal Distribution System Horizon Planning ndash; Part I: Formulation. IEEE Trans. Power Syst. 2007, 22, 791-799. [CrossRef]

59. Türkay, B.; Artaç, T. Optimal Distribution Network Design Using Genetic Algorithms. Electr. Power Compon. Syst. 2005, 33, 513-524. [CrossRef]

60. Mateo, C.; Gómez, T.; Sanchez-Miralles, Á.; Peco, J.P.; Candela, A. A Reference Network Model for Large-Scale Distribution Planning with Automatic Street Map Generation. IEEE Trans. Power Syst. 2011, 26, 190-197. [CrossRef]

61. Ziari, I.; Ledwich, G.; Ghosh, A. Optimal integrated planning of MV-LV distribution systems using DPSO. Electr. Power Syst. Res. 2011, 81, 1905-1914. [CrossRef]

(C) 2017 by the authors. Licensee MDPI, Basel, Switzerland. This article is an open access article distributed under the terms and conditions of the Creative Commons Attribution (CC BY) license (http://creativecommons.org/licenses/by/4.0/). 